\title{
Synaptic Plasticity in the Lateral Amygdala: A Cellular Hypothesis of Fear Conditioning
}

\author{
Hugh T. Blair, Glenn E. Schafe, Elizabeth P. Bauer, Sarina M. Rodrigues, \\ and Joseph E. LeDoux ${ }^{1}$
}

Center for Neural Science, New York University, New York, New York 10003, USA

\begin{abstract}
Fear conditioning is a form of associative learning in which subjects come to express defense responses to a neutral conditioned stimulus (CS) that is paired with an aversive unconditioned stimulus (US). Considerable evidence suggests that critical neural changes mediating the CS-US association occur in the lateral nucleus of the amygdala (LA). Further, recent studies show that associative long-term potentiation (LTP) occurs in pathways that transmit the CS to LA, and that drugs that interfere with this LTP also disrupt behavioral fear conditioning when infused into the LA, suggesting that associative LTP in LA might be a mechanism for storing memories of the CS-US association. Here, we develop a detailed cellular hypothesis to explain how neural responses to the CS and US in LA could induce LTP-like changes that store memories during fear conditioning. Specifically, we propose that the CS evokes EPSPs at sensory input synapses onto LA pyramidal neurons, and that the US strongly depolarizes these same LA neurons. This depolarization, in turn, causes calcium influx through NMDA receptors (NMDARs) and also causes the LA neuron to fire action potentials. The action potentials then back-propagate into the dendrites, where they collide with CS-evoked EPSPs, resulting in calcium entry through voltage-gated calcium channels (VGCCs). Although calcium entry through NMDARs is sufficient to induce synaptic changes that support short-term fear memory, calcium entry through both NMDARs and VGCCs is required to initiate the molecular processes that consolidate synaptic changes into a long-term memory.
\end{abstract}

Classical fear conditioning is a form of associative learning in which subjects come to express fear responses to a neutral conditioned stimulus (CS) that is paired with an aversive unconditioned stimulus (US). As a result of this pairing, the CS acquires the capacity to elicit behavioral, autonomic, and endocrine responses that are characteristically expressed in the presence of danger (Blanchard and Blanchard 1969; Bolles and Fanselow 1980; Smith et al. 1980). Because fear conditioning is rapidly acquired and persistent, involves well-defined stimuli and responses, occurs widely in the animal kingdom, and involves similar neural circuits in different vertebrate species, it has emerged as an especially useful behavioral model for investigating the neurobiological mechanisms of learning and memory (see Davis and Lee 1998; Maren 1999; LeDoux 2000; Rogan et al. 2001).

In fear conditioning, as in many other forms of associative learning, subjects respond differently to the CS after it has been paired with the US. Hence, the US is believed to modify the manner in which the CS is processed in the brain. A major challenge is to explain how such modifications take place at the cellular level.

It has long been believed that the critical cellular changes underlying learning involve alterations in synaptic

${ }^{1}$ Corresponding author.

E-MAIL ledoux@cns.nyu.edu; FAX (212) 995-4704.

Article and publication are at http://www.learnmem.org/cgi/doi/ $10.1101 / \mathrm{lm} .30901$. transmission (Cajal 1909; Hebb 1949; Eccles 1965; Kandel and Spencer 1968). In perhaps the most influential statement of the synaptic hypothesis, Hebb (1949) proposed that when two interconnected neurons fire at the same time, the synapses between them become stronger, and remain stronger for a long time afterward. This form of synaptic strengthening has come to be called Hebbian synaptic plasticity.

Hebbian plasticity could provide a neural mechanism for long-term memory storage during classical conditioning (see Kandel and Spencer 1968; McNaughton et al. 1978; Levy and Steward 1979; Hawkins et al. 1983; Kelso et al. 1986). When a neutral CS is paired with a US, neurons that respond to the CS become activated simultaneously with neurons that respond to the US. According to Hebb's theory, synaptic connections between these neural populations should become stronger, thereby storing a memory for the association between the CS and US.

For Hebbian plasticity to explain fear conditioning at the level of cells and synapses, it is necessary to identify biological mechanisms that allow individual neurons to detect and record that the CS and US have been simultaneously activated. Several mechanisms for so-called "coincidence detection" have been discovered (see Konnerth et al. 1996; Tsien 2000). Here we propose a cellular hypothesis about how specific coincidence detection mechanisms in the amygdala might mediate Hebbian synaptic plasticity

LEARNING \& MEMORY 8:229-242 @ 2001 by Cold Spring Harbor Laboratory Press ISSN1072-0502/01 \$5.00

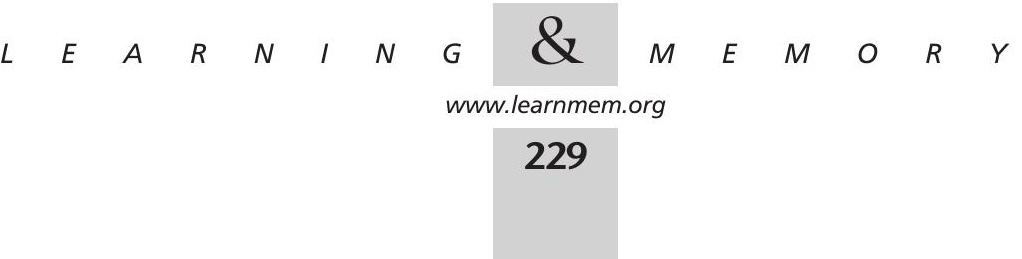


and thereby explain how a memory of the CS-US association is formed during fear conditioning.

\section{Neural Circuits Underlying Associative Fear Conditioning}

Fear conditioning depends critically upon the transmission of sensory information about the CS and US to the amygdala (Campeau and Davis 1995; Davis and Lee 1998; Fanselow and LeDoux 1999; LeDoux 2000). Much of the evidence for this has come from studies of auditory fear conditioning, in which a neutral auditory tone (the CS) is paired with electric shock (the US). The lateral nucleus of the amygdala (LA) receives direct auditory sensory inputs from the thalamus and cortex, and serves as the sensory interface of the amygdala (Pitkänen et al. 1997; McDonald 1998; Doron and LeDoux 1999) (Fig. 1A). LA sends direct and indirect projections to the central nucleus of the amygdala (CE) (Pare et al. 1995; Pitkänen et al. 1997), which in turn projects to brainstem and hypothalamic regions that govern defensive behaviors and accompanying autonomic and endocrine responses. Damage to LA and CE prevent the conditioning of fear responses to an auditory CS (LeDoux et al. 1990; Kapp et al. 1992; Davis and Lee 1998; Amoropranth et al. 2000; Nader et al. 2000; Goosens and Maren 2001). Although damage to other amygdala regions was ineffective in two of the studies (Amoropranth et al. 2000; Nader et al. 2000), in one damage to the basal nucleus also had an effect (Goosens and Maren 2001). Thus, the amygdala, and specifically the LACE circuitry, provides an anatomical channel through which the CS, after pairing with the US, can gain access to defense response systems.

LA is the first stage of processing for auditory inputs to the amygdala, and Figure 1B illustrates how Hebbian plas-

A
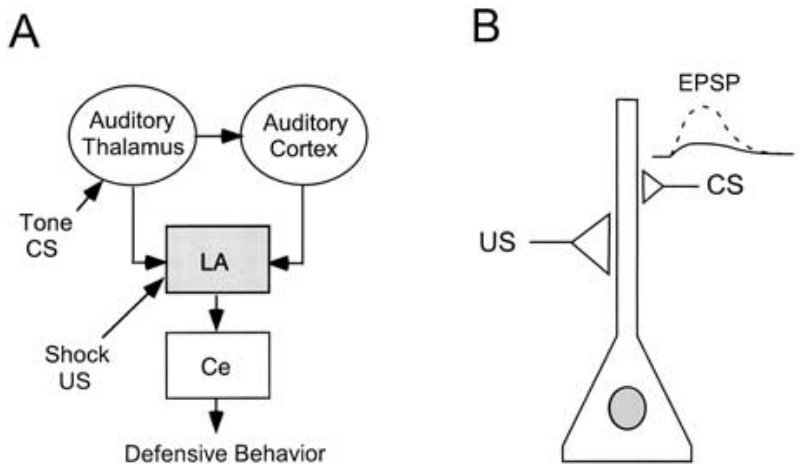

Figure 1 LA neurons provide a pathway by which auditory signals can gain access to circuits controlling defensive responses. $(A)$ During auditory fear conditioning, sensory information about the tone CS reaches LA via a thalamic pathway and a cortical pathway. $(B)$ Auditory synaptic inputs to individual LA neurons may be weak prior to conditioning (small EPSP, solid line), but become strengthened by Hebbian plasticity (large EPSP, broken line) after they are activated simultaneously with US inputs that strongly depolarize the LA neuron. ticity could mediate memory storage at synaptic inputs to a single LA neuron. According to Hebb's rule, if the same cells that are weakly activated by the auditory CS are, at about the same time, strongly activated by the US, the synapses processing the CS should be strengthened. This property of Hebb's rule, whereby weak synaptic inputs can be strengthened by coactivation with strong inputs, is commonly referred to as the "associative" property of Hebbian learning. As a result of associative strengthening of CS inputs, the CS could acquire the ability to activate amygdala-driven defensive responses in the absence of the US. Whereas the CS clearly acquires this ability, an important issue is whether Hebbian plasticity occurs in these circuits during fear conditioning and, if so, whether it accounts for the associative conditioning of fear responses to the CS.

Several lines of evidence, when considered together, strongly suggest that the LA is a key locus of Hebbian plasticity, and thus a site in which critical elements of the CSUS association are stored during auditory fear conditioning. First, damage restricted to the LA prevents the acquisition and expression of fear responses to an auditory CS (LeDoux et al. 1990; Amorapanth et al. 2000; Goosens and Maren 2001; Nader et al, 2001) showing that the LA is a necessary component of the circuitry through which the CS-US association is formed. Second, functional inactivation of LA (and adjacent areas) with the GABA agonist muscimol during conditioning impairs the acquisition of auditory CS-elicited fear responses (Helmstetter and Bellgowan 1994; Muller et al. 1997; Wilensky et al. 1999, 2000), showing that neural activity in LA during conditioning is required for this type of fear learning to take place. Third, the auditory CS and nociceptive US converge on single neurons in LA (Romanski et al. 1993; Blair et al. 2000), providing a substrate through which the US might modify the processing of the CS. Fourth, neural responses evoked in LA by the auditory CS are enhanced when the CS is paired with US (Quirk et al. 1995, 1997; McKernnen and Shinnick-Gallagher 1997; Rogan et al. 1997; Collins and Pare 2000; Repa et al. 2001), supporting the Hebbian prediction that temporal overlap of the CS and US leads to the strengthening of the synaptic connections activated by the CS. Fifth, disruption of macromolecular synthesis in LA and surrounding areas prevents the consolidation of long-term memory for associative auditory fear conditioning (Bailey et al. 1999; Nader et al. 2000; Schafe et al. 2000), consistent with the widely held belief that macromolecular synthesis is essential for the conversion of short to long-term memory in neurons that store associative memories (Davis and Squire 1984; Goelet et al. 1986; Dudai 1989; Bailey et al. 1996; Kandel 1997).

Although these findings provide strong evidence that the amygdala stores long-term memories of the CS-US association during fear conditioning, an alternative view is that the amygdala is necessary for the performance of conditioned responses and the modulation of memory in other

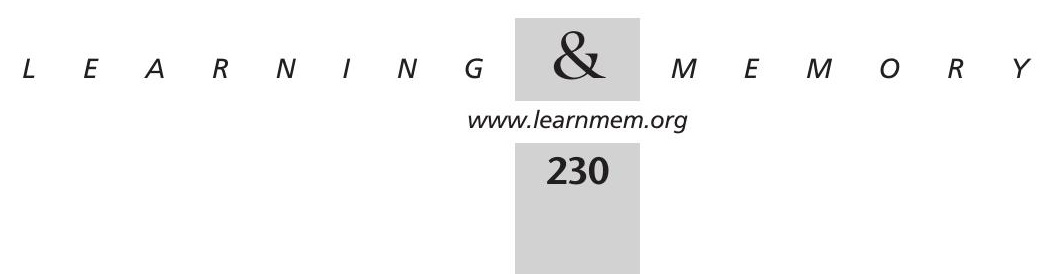


brain regions, but the locus of the plasticity that underlies the long-term memory of fear conditioning is elsewhere (Cahill and McGaugh 1998; Cahill et al. 1999). Key to this argument is the fact that immediate post-training manipulations of the amygdala (especially the LA and the adjacent basal nucleus) influence the strength of memory in a variety of different appetitive and aversive instrumental learning tasks. However, memory of classical Pavlovian fear conditioning is not affected by immediate post-training manipulations of the amygdala in the same manner as these instrumental tasks (Wilensky et al. 2000; Lee et al. 2001a). This indicates that whereas the amygdala clearly participates in the modulation of long-term memories stored in other brain regions, this modulation is not essential for the amygdaladependent aspects of Pavlovian fear conditioning.

In summary, available evidence strongly suggests that Hebbian neural changes occur in LA during fear conditioning, and these changes are critical for the conditioning of fear responses to an auditory CS. Although LA may not be the only site of such changes (e.g., Weinberger 1995; Maren et al. 2001; Poremba and Gabriel 2001), it is very likely a site where changes relevant to behavioral fear learning occur. We now discuss synaptic events that might underlie these neural changes in LA.

\section{Synaptic Mechanisms for Associative Learning}

At the time Hebb (1949) proposed his influential theory, there was little evidence available to support the view that the connection between two neurons increases when those neurons are simultaneously active. However, later studies showed that high-frequency stimulation of afferents to the hippocampus leads to a long-term enhancement of synaptic transmission, called long-term potentiation (LTP) (Bliss and Lomo 1973). It has been shown subsequently that LTP can occur in many structures throughout the brain, and that at certain synapses, LTP exhibits two key properties that are predicted by Hebb's theory. First, LTP at certain synapses is associative, in that coactivation of weak inputs and strong inputs onto the same neuron can lead to strengthening of the weak inputs (McNaughton et al. 1978; Levy and Steward 1979). Second, such LTP is synapse specific, in that synaptic strengthening occurs only at synapses of active, but not inactive, presynaptic afferents to the postsynaptic cell (Andersen et al. 1977; Lynch et al. 1977). LTP that exhibits these two properties - associativity and synapse specificity - is commonly referred to as associative or Hebbian LTP. Hebbian LTP has gained prominence as the leading biological model of associative memory formation (see Brown et al. 1988; Bliss and Collingridge 1993; Martin et al. 2000; Hölscher 2001; Rogan et al. 2001).

Much of what has been learned about the cellular mechanisms of Hebbian LTP has come from studies of pyramidal neurons in the hippocampus and neocortex (for review, see Bliss and Collingridge 1993; Malenka and Nicoll 1999). Our hypothesis about the cellular mechanisms of fear conditioning in the amygdala is in part dependent on mechanisms discovered in studies of these other structures, so we will briefly summarize some of the relevant findings.

Associative LTP can be induced experimentally in several different ways, but two are particularly relevant for the present discussion. The first, as already mentioned, is the delivery of a high-frequency train of pulses, or tetanus, to presynaptic fibers. This tetanic stimulation is so intense that it causes strong depolarization of postsynaptic cells, and thus, pre- and postsynaptic neurons are simultaneously activated to induce Hebbian LTP. The other method of LTP induction is paired stimulation, in which the presynaptic pathway is weakly stimulated, whereas the postsynaptic neuron is concurrently depolarized by current injection (Kelso et al. 1986; Malinow and Miller 1986; Wigström and Gustafsson 1986; Magee and Johnston 1997; Markram et al. 1997; Bi and Poo 1998;). Again, combined pre and postsynaptic activity occurs to produce Hebbian LTP.

Associative LTP, whether induced by tetanic stimulation or pairing, generally depends on the influx of calcium into the postsynaptic cell (see Malenka 1991). The rise in calcium then triggers a cascade of other intracellular processes that ultimately induce synaptic enhancement (Malenka 1991; Frank and Greenberg 1994; Lisman 1994; Carew 1996; Kandel 1997; Elgersma and Silva 1999; Sweatt 1999, 2000). In hippocampal and cortical pyramidal neurons, these calcium-activated intracellular processes are believed to enhance synaptic strength by increasing the amount of glutamate-evoked current that flows into the postsynaptic cell through D,L- $\alpha$-amino-3-hydroxy-5-methyl4-isoxazole proprionic acid receptors (AMPARs) in response to presynaptic transmitter release (Kauer et al. 1988; Muller et al. 1988; Isaac et al. 1995; Liao et al. 1995).

It appears that the reason some forms of LTP obey a Hebbian rule is that the calcium influx that underlies the synaptic enhancement only occurs when the pre- and postsynaptic cells are concurrently activated, and not when either cell is activated alone. There are two major mechanisms known for calcium influx into the postsynaptic cell during associative LTP. The first involves the N-methyl-Daspartate class of glutamate receptors (NMDARs; Watkins and Olverman 1987; Regehr and Tank 1990; Monyer et al. 1992; Nakanishi 1992; Bliss and Collingridge 1993; Hollmann and Heinemann 1994; Malenka and Nicoll 1999), and the second involves voltage-gated calcium channels (VGCCs; Grover and Teyler 1990; Aniksztejn and Ben-Ari 1991; Mikayawa et al. 1992; Sabatini and Svoboda 2000). Below, we consider how each of these can subserve coincidence detection and thereby mediate Hebbian synaptic plasticity.

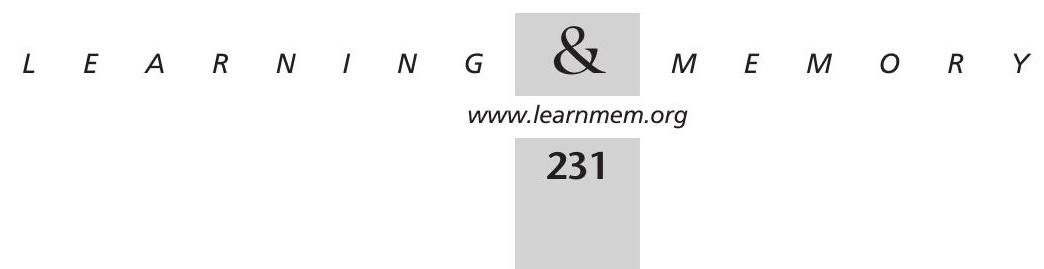




\section{Role of NMDARs and VGCCs in Hebbian Coincidence Detection}

NMDARs are ligand-gated ion channels that are typically blocked by magnesium at the resting membrane potential. The magnesium block is removed during depolarization of the postsynaptic cell, but the receptor channel cannot open unless presynaptically released glutamate is bound to the receptor when the magnesium block is removed. When both of these conditions are met (postsynaptic depolarization combined with presynaptic stimulation), calcium enters the postsynaptic cell through NMDARs. NMDARs are thus well suited to function as Hebbian coincidence detectors because they pass calcium only when pre- and postsynaptic cells are activated at the same time. Because only the synapses that are actively binding glutamate during the postsynaptic response are modified, NMDARs can account for the synapse specificity in Hebbian LTP. Hebbian LTP was initially thought to be synonymous with NMDA-dependent LTP, but subsequent studies have shown that Hebbian LTP does not always require NMDA receptors. NMDA-independent LTP usually requires calcium entry into the postsynaptic cell through L-type VGCCs. (Grover and Teyler 1990; Aniksztejn and Ben-Ari 1991; Mikayawa et al. 1992). As this VGCC-dependent (but NMDA-independent) LTP can be both associative and synapse specific, it raises the possibility that VGCCs might be able to function as Hebbian coincidence detectors.

How might VGCCs serve to detect concurrent activity in the pre- and postsynaptic cell? L-type VGCCs have a high activation threshold, so they are opened only when the postsynaptic cell becomes strongly depolarized. It has been proposed that under natural physiological conditions, VGCCs are opened by strong depolarization resulting from back-propagating action potentials (BPAPs) that invade the dendrites of the postsynaptic cell when it fires a spike (Jaffe et al. 1992; Yuste and Tank 1996; Magee and Johnston 1997; Stuart et al. 1997; Johnston et al. 1999). Contradicting this idea, recent data suggests that the activation kinetics of L-type VGCCs may be too slow for BPAPs to open them, because the depolarization that occurs during a BPAP is quite brief and it may not last long enough to fully activate L-type VGCCs (Mermelstein et al. 2000). However, it has been shown that BPAPs can be prolonged and amplified in the dendrites when they collide with EPSPs (Magee and Johnston 1997; Stuart and Hausser 2001), and this amplification of BPAPs by EPSPs leads to elevated calcium entry and LTP near active synapses (Magee and Johnston 1997). Thus, the preferred conditions for opening VGCCs may occur when an EPSP, triggered by the presynaptic cell, occurs nearly simultaneously with a BPAP, generated by the postsynaptic cell. VGCCs are found in dendrites and spines near glutamatergic synapses (Sabatini and Svoboda 2000), so calcium entry through these channels could strengthen synapses by activating second messengers in much the same way that calcium influx through NMDA channels does (Magee and Johnston 1997; Johnston et al. 1999). Hence, VGCCs could function as Hebbian coincidence detectors to support associative LTP, if elevated calcium entry through VGCCs occurs mainly when presynaptic EPSPs occur simultaneously with postsynaptic BPAPs (Magee and Johnston 1997). Furthermore, such LTP could be synapse specific, as amplification of BPAPs by EPSPs and resultant calcium entry is probably confined to a localized region of the dendrite near activated synapses (Stuart and Hausser 2001).

In summary, NMDARs and VGCCs provide two possible mechanisms for Hebbian coincidence detection during associative LTP. Which of these mechanisms becomes engaged to induce LTP may depend upon the properties of a given synapse, and also upon the exact pattern of neural activity that leads to LTP induction. Below, we will present evidence suggesting that both NMDARs and VGCCs in LA participate together in the synaptic plasticity that underlies long-term memory storage during fear conditioning.

\section{Hebbian LTP in LA}

For LTP to account for memory formation, it would be necessary to show that the same mechanisms engaged by artificial stimulation in LTP experiments are also triggered by natural activity patterns during learning. Indirect support for this notion comes from studies showing that hippocampal-dependent memory can be impaired or enhanced in behaving animals by pharmacological and genetic manipulations that alter hippocampal LTP (Davis et al. 1992; Bach et al. 1996; Mayford et al. 1996; Tsien et al. 1996; Tang et al. 1999). But despite advances such as these, it has been difficult to clarify the contribution of specific hippocampal circuits to memory, and thus to relate LTP at specific synapses to memory (see Barnes 1995; Eichenbaum 1997; Stevens 1998; Martin et al. 2000).

Given that plasticity is likely to occur during fear conditioning at specific synapses in LA, and that this plasticity is required to store memories of conditioned fear (Fanselow and LeDoux 1999; Maren 1999; LeDoux 2000), it may be easier to gain a precise understanding of how LTP participates in memory storage in LA than in the hippocampus (Eichenbaum 1997; Stevens 1998; Martin et al. 2000; Rogan et al. 2001). Evidence to be reviewed below suggests that Hebbian LTP occurs in LA, both in vivo and in vitro, and fear conditioning and Hebbian LTP in LA depend on similar mechanisms, the combined action of NMDARs and VGCCs. In this section, we summarize the evidence for the existence of Hebbian plasticity in LA, and then describe the mechanisms that have been uncovered. In a later section, we explore the relation between the mechanisms of LTP and fear conditioning.

The principle projection cells found in LA and adjacent basal nucleus are spiny, glutamatergic pyramidal neurons

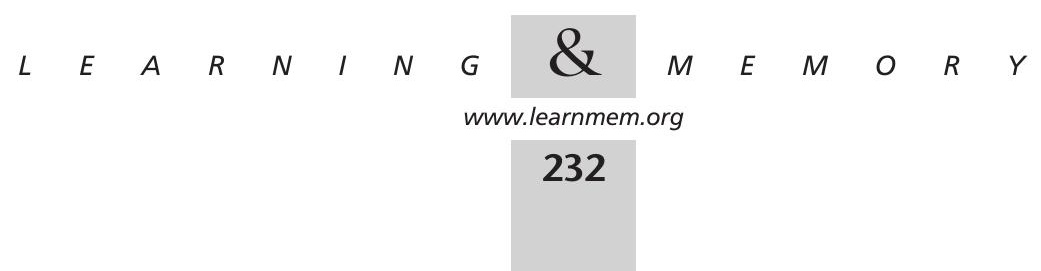


(McDonald 1984; Washburn and Moises 1992; Rainnie et al. 1993). These neurons share morphological and physiological features with pyramidal cells of the hippocampus and neocortex, where LTP has been extensively studied previously. LA pyramidal cells receive excitatory inputs from presynaptic neurons in the auditory thalamus and cortex (see Fig. 1). Anatomical studies have shown that glutamate is present in the presynaptic terminals in LA (LeDoux and Farb 1991; Farb et al. 1992), and that both AMPARs and NMDARs are localized in spines and dendritic segments postsynaptic to these terminals (Farb et al. 1995; Farb and LeDoux 1997, 1999). Also, physiological studies have shown that both AMPARs and NMDARs contribute to EPSPs elicited from LA cells by presynaptic stimulation of auditory inputs (Li et al. 1995, 1996; Weisskopf and LeDoux 1999). Auditory input synapses in LA therefore possess the essential mechanisms of glutamatergic transmission that are known to support Hebbian LTP.

Several studies have shown that associative fear conditioning is accompanied by an enhancement of synaptic transmission at auditory input synapses in LA, findings that are consistent with the view that Hebbian learning occurs in LA during fear conditioning. For example, auditory stimuli elicit field potentials in the LA of awake, freely behaving rats, and induction of LTP in the thalamic input to LA leads to an enhancement of these auditory responses (Rogan and LeDoux 1995). Additionally, fear conditioning in awake, freely behaving rats results in a potentiation of field potentials recorded from LA in awake rats that resembles changes seen after LTP induction in vivo (Rogan et al. 1997), and also potentiates synaptic inputs to LA recorded in post-mortem brain slices (McKernan and Shinnick-Gallagher 1997). Further, following fear conditioning, single unit responses evoked by an auditory CS are enhanced in LA (Quirk et al. 1995, 1997; Collins and Pare 2000; Maren 2000; Repa et al. 2001). Although these studies indicate that associative fear learning produces commensurate changes in synaptic activity in LA, they have provided little insight into the cellular mechanisms underlying the synaptic changes.

Cellular mechanisms of LTP have been investigated mostly at synaptic inputs to LA in vitro using whole-cell recordings of intracellular excitatory postsynaptic potentials (EPSPs) or extracellular recordings of field EPSPs in amygdala brain slices. The mechanisms involved are dependent on the manner in which LTP is induced.

Several studies have shown that, in amygdala brain slices, LTP induced by tetanic stimulation of the cortical or thalamic inputs to LA is abolished by bath application of the NMDAR antagonist APV during the tetanus (Huang and Kandel 1998; Bauer et al. 2000; Huang et al. 2000). In studies involving intracellular recordings, the synaptic changes were also abolished by loading the postsynaptic cell with the calcium chelator BAPTA, indicating that induction of
LTP required calcium entry into the postsynaptic cell (Huang and Kandel 1998).

The fact that tetanus-induced LTP in LA involves NMDARs suggests that this form of LTP requires coactivation of pre- and postsynaptic cells, and thus may be Hebbian in nature. However, during the tetanus protocol, concurrent pre- and postsynaptic activity is achieved by strong stimulation of a single presynaptic input pathway to LA. In contrast, associative learning that occurs during fear conditioning is thought to require the conjunctive activation of weak presynaptic CS inputs to LA during strong depolarization of these same neurons by the US. Hence, natural activity patterns that occur in LA during behavioral fear learning may be very different from activity that occurs during tetanic stimulation. As discussed above, LTP can also be induced by pairing weak, subthreshold presynaptic stimulation with a strong postsynaptic depolarization that causes an action potential to occur in the postsynaptic cell (Kelso et al. 1986; Malinow and Miller 1986; Wigstrom and Gustafsson 1986; Magee and Johnston 1997; Markram et al. 1997; Bi and Poo 1998). Such a pairing protocol may better approximate the stimulus conditions that occur during associative learning, because the presynaptic stimulation is like a weak CS that activates the postsynaptic neuron, and the postsynaptic depolarization is like a strong activation of the same cell by the US (Kelso and Brown 1986; Kelso et al. 1986).

Several studies have shown that pairing weak stimulation of either cortical or thalamic inputs with strong postsynaptic depolarization of LA neurons can induce LTP. Huang and Kandel (1998) induced LTP in the cortico-LA pathway by giving low-frequency $(0.2 \mathrm{~Hz})$ presynaptic stimulation pulses paired with prolonged $(50 \mathrm{~ms})$ injection of current (2-4 nA) into the postsynaptic LA neuron (Huang and Kandel 1998). This LTP was attenuated, but not completely blocked, by NMDA antagonists. Huang and Kandel (1998) speculated that the NMDA-independent component of this pairing-induced LTP might depend on VGCCs, but they did not experimentally test this hypothesis.

Weisskopf et al. (1999) used a pairing protocol to explore the role of NMDARs and VGCCs in LTP in the thalamoLA pathway. In their repeated pairing protocol, trains of 10 presynaptic pulses at $30 \mathrm{~Hz}$ were paired with brief postsynaptic depolarizations (1 $\mathrm{nA}$ for $5 \mathrm{~ms}$ ) delivered 5-10 $\mathrm{msec}$ after the onset of each EPSP in the train. In this protocol, postsynaptic spikes were typically not elicited by the relatively weak presynaptic stimulation alone, but were reliably evoked by the strong postsynaptic depolarization pulses. The pairing train was given 15 times at 10 -sec intervals, and produced robust LTP of the EPSP elicited by thalamic stimulation. Pairing-induced LTP of the thalamo-LA pathway did not affect the EPSP elicited by cortical stimulation, showing that this form of LTP is associative and synapse specific. Further, the LTP was not at all affected by the NMDA antagonists APV and MK-801 (Weisskopf et al. 1999), indicat-

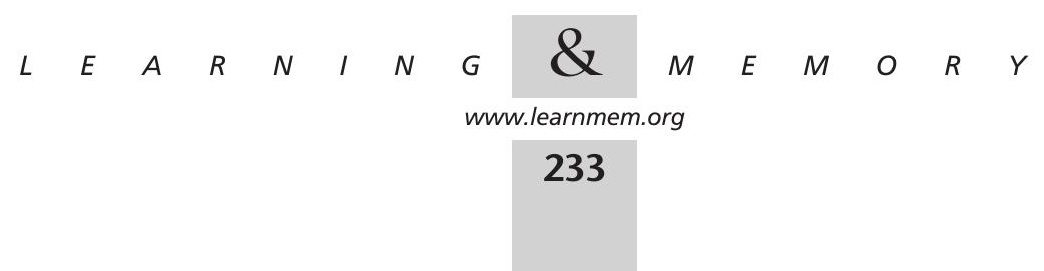


ing that NMDARs are not involved. The LTP was instead abolished by bath application of the L-type VGCC antagonist nifedipine, as well as by loading the postsynaptic cell with BAPTA (Weisskopf et al. 1999). Subsequent studies showed that this form of LTP could also be blocked by the L-type VGCC antagonist verapamil (Bauer et al. 2000). These findings indicate that pairing-induced LTP in the thalamo-LA pathway requires L-type VGCCs, but not NMDARs.

Together, the above findings suggest that Hebbian LTP in LA can involve either NMDARs or VGCCs, depending on the stimulation conditions. Sustained tetanization of presynaptic inputs to LA produces prolonged stimulation of the synapse that permits sustained calcium entry through NMDARs. This sustained NMDA-dependent calcium entry is sufficient to induce LTP without additional calcium entry through VGCCs, so tetanus-induced LTP depends mainly on NMDARs (Huang and Kandel 1998; Bauer et al. 2000), and not on VGCCs (Bauer et al. 2000). Conversely, associative LTP that depends on VGCCs and not on NMDARs can be induced by giving precisely timed postsynaptic depolarizations that elicit spikes following each EPSP in a synchronous train (Weisskopf et al. 1999). This form of LTP may depend on VGCCs because precisely timed postsynaptic depolarizations that follow each synaptic EPSP elicit BPAPs that collide with EPSPs (Magee and Johnston 1997; Stuart and Hausser 2001), and thereby amplify calcium entry through VGCCs at active synapses. When these collisions of the BPAP and EPSP are induced repeatedly in a synchronous train, they could cause enough calcium influx through VGCCs to induce LTP without additional calcium entry through NMDARs (Weisskopf et al. 1999).

Although these experiments show that it is possible to artificially induce LTP in LA that requires VGCCs but not NMDARs, or vice versa, this does not mean that LTP must always depend on only one of these mechanisms, and not the other. In the hippocampus, some stimulation protocols produce LTP that requires both NMDARs and VGCCs (Huber et al. 1995; Magee and Johnston 1997; Nishiyama et al. 2000). Further, as noted, Huang and Kandel found that NMDA blockade only partly disrupted LTP in their pairing protocol, a finding that is consistent with a role for VGCCs in the residual LTP. We now review evidence that during fear learning, LTP is induced in LA by natural patterns of stimulation that occur in response to the CS and US, and that this Hebbian plasticity requires both NMDARs and VGCCs.

\section{Role of NMDARs and VGCCs in Fear Conditioning}

As reviewed above, there is strong evidence that memory storage during fear conditioning occurs in LA, and that a Hebbian process is involved. Because Hebbian synaptic plasticity typically requires activation of either NMDARs or VGCCs (or both), several studies have sought to determine whether fear conditioning depends upon the function of NMDARs and VGCCs in LA.

Bauer et al. (2000) found that infusion of the L-type VGCC blocker verapamil into LA during training blocked the acquisiton of fear conditioning, but did not impair the expression of previously learned conditioned fear responses. They also examined the effects of verapamil on synaptic transmission and LTP induction in amygdala brain slices, and found that verapamil had no effect on synaptic transmission, but prevented LTP induction, in agreement with previous studies in which LTP was impaired by applying nifedipine to block VGCCs (Weisskopf et al. 1999). Ltype VGCCs in LA thus appear to play a parallel role in behavioral fear conditioning and pairing-induced associative LTP.

A number of behavioral studies have shown that infusion of the NMDA antagonist APV into LA and the adjacent basal nucleus impairs acquisition of fear learning in a variety of tasks, including auditory fear conditioning (Lee and Kim 1998), contextual fear conditioning (Fanselow and Kim 1994; Maren et al. 1996), and fear-potentiated startle (Miserendino et al. 1990; Campeau et al. 1992; Gewirtz and Davis 1997; Walker and Davis 2000). This suggests that NMDAdependent synaptic plasticity in LA is required for learning to occur. However, NMDARs are known to play a significant role in synaptic transmission in LA (Gean et al. 1993; Li et al. 1996; Lee and Kim 1998; Weisskopf and LeDoux 1999; Blair and LeDoux 2001). Therefore, infusion of NMDA antagonists into LA may not only impair synaptic plasticity, but also block synaptic transmission. This probably explains why, in several studies, NMDA blockade not only impairs learning of new fear responses, but also prevents the expression of previously learned fear responses (Maren et al. 1996; Lee and Kim 1998; Fendt 2001; Lee et al. 2001b). The main exception is studies of fear potentiated startle by Davis and colleagues, who have found that APV does block acquisition without affecting expression (Miserendino et al. 1990; Campeau et al. 1992; Gewirtz and Davis 1997; Walker and Davis 2000). However, another recent study has reported that APV affects both acquisition and expression of fear potentiated startle (Fendt 2001).

It is difficult to interpret the effects of APV infusions on synaptic plasticity in behaving rats, as the behavioral studies reviewed above have produced conflicting evidence that does not consistently and unequivocally distinguish effects on synaptic transmission from effects on plasticity. However, recent experiments using an alternative method provide a means for more clearly distinguishing the role of NMDARs in synaptic plasticity and transmission in LA during fear conditioning.

NMDARs are heteromeric molecules, consisting of two NR1 subunits plus some combination of subunits from the NR2 class, the NR2A, NR2B, NR2C, or NR2D subunits (Schoepfer et al. 1994; Behe et al. 1995). Interestingly,

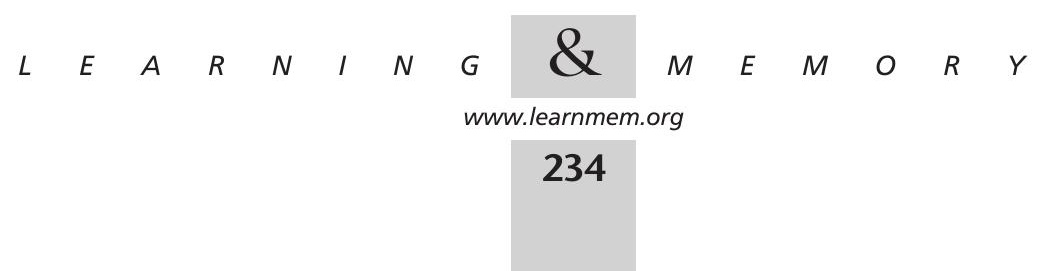


NMDARs incorporating NR2B subunits generate longer EPSPs than those incorporating only NR2A subunits (Moyner et al. 1994). Further, it has been shown that hippocampal LTP is accompanied by increased tyrosine phosphorylation of NMDARs at the NR2B subunit (Rosenblum et al. 1996; Rostas et al. 1996), suggesting a link between the NR2B subunit and synaptic plasticity that may underlie memory storage. Supporting this hypothesis, the NR2B subnit in the insular cortex has been implicated in memory for novel tastes (Rosenblum et al. 1997), and genetic overexpression of the NR2B subunit in hippocampus leads to increased LTP and enhanced learning of hippocampal-dependent tasks (Tang et al. 1999).

APV is a nonselective antagonist that blocks all NMDARs, regardless of their molecular composition. NMDARs that incorporate the NR2B subunit can be selectively blocked by use of the NR2B-specific antagonist ifenprodil. Rodrigues et al. (2001) infused ifenprodil into LA during the acquisition phase of auditory fear conditioning to a tone CS. As with APV, conditioning was impaired when rats were tested drug free after training. However, unlike the effects of APV, infusion of ifenprodil into LA prior to testing did not block the expression of previously learned tone conditioning. This suggests that ifenprodil selectively blocks synaptic plasticity in LA, without disrupting normal synaptic transmission. Hence, NMDARs in LA that incorporate the NR2B subunit may be particularly important for synaptic plasticity that occurs during fear learning, whereas other classes of NMDARs may be more important for normal synaptic transmission. It thus appears that NMDARs do contribute significantly to fear conditioning in LA, and that the NR2B subunit plays an important role.

In summary, both NMDARs and VGCCs in LA are probably necessary at the time of learning for fear conditioning to occur, but they are not necessary for the expression of previously learned fear. A likely explanation for these findings is that NMDARs and VGCCs are needed for Hebbian LTP to occur in LA at the time of learning.

\section{Relating LTP and Fear Conditioning: A Cellular Hypothesis}

On the basis of evidence reviewed thus far, we propose that LTP may be induced in LA during auditory fear conditioning in the following way (Fig. 2). When an auditory CS is presented, glutamate is released from sensory presynaptic terminals in LA, and this glutamate binds to AMPARs and NMDARs on dendritic spines of the postsynaptic LA pyramidal neuron. The resulting current influx through AMPARs and NMDARs generates an EPSP in the LA neuron. The size of this EPSP depends critically on the amount of postsynaptic AMPA current, for two reasons, because the large initial component of the EPSP is mainly AMPA dependent, although not exclusively so in LA (e.g., Weisskopf and LeDoux 1998) and because AMPA-mediated depolarization is a necessary precondition for removing the magnesium block from NMDA receptors. Hence, without enough AMPA current, there will be very little NMDA current, and the EPSP will be small and brief.

We postulate that prior to conditioning, the CS-evoked EPSP is relatively small and brief, due to a low amount of current influx through AMPARs when glutamate is released from presynaptic terminals (Fig. 2, left; see Isaac et al. 1995; Liao et al. 1995). The small, brief EPSP is not very effective at removing the magnesium block from NMDARs, or at opening VGCCs, so very little calcium enters the postsynaptic cell in response to presentation of the CS alone. However, even though NMDARs remain blocked by magnesium, they are now binding glutamate that was released from the sensory presynaptic terminal. Consequently, these NMDARs are eligible to pass calcium if the LA neuron becomes further depolarized to remove the magnesium block.

The same LA neurons that receive input from the CS are strongly depolarized when the US occurs (Fig. 2, middle). The fact that this occurs is suggested by studies showing that an electric shock US elicits bursts of action potentials from LA cells in awake, behaving rats (Blair and LeDoux 2000). Hence, depolarization of the dendrites by the US could cause significant calcium influx through those NMDARs that have recently bound glutamate that was released during the CS (Fig. 2, arrow 1). This unblocking of NMDARs could, in turn, result in a large NMDA-mediated EPSP that further depolarizes the LA neuron. It has been proposed that such NMDA-mediated EPSPs may be well suited for opening VGCCs (Mermelstein et al. 2000). How-

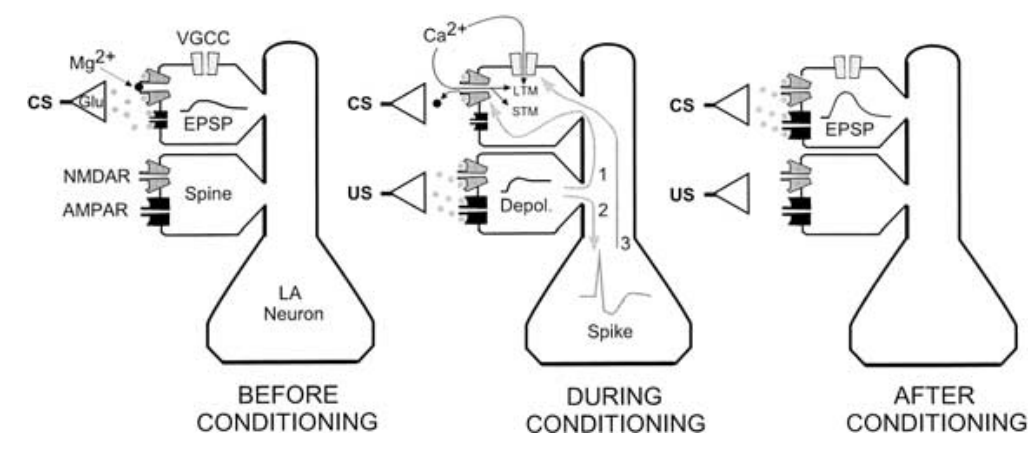

Figure 2 Cellular hypothesis of fear conditioning in LA. When the tone CS is presented before fear conditioning (left), glutamate is released at sensory synaptic inputs to LA neurons, and binds to AMPARs and NMDARs. The CS elicits only a small EPSP from the LA neurons, but it binds glutamate to NMDARs, making them eligible to pass calcium in the event of strong postsynaptic depolarization by the US (middle, arrow 1). Calcium entry through NMDARs induces short-term LTP at the synapse, but in to stabilize these changes into long-term memories, VGCCs must be activated by a BPAP, which occurs when the US elicits a spike from the LA neuron (middle, arrow 2) that backpropagates into the dendrites to collide with CS-evoked EPSPs and open VGCCS (middle, arrow 3). After fear conditioning, the CS-evoked EPSP is larger, possibly due to an increase in AMPA currents following LTP (right).

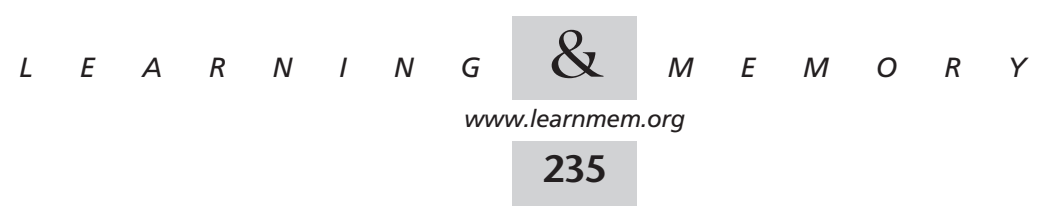


ever, a prolonged NMDA-mediated EPSP that exceeds the threshold for opening VGCCs might depolarize a large region of the dendritic tree, could open VGCCs at both active and inactive synapses. Hence, the opening of VGCCs by NMDA-mediated EPSPs would not be synapse specific. However, calcium entry through VGCCs might be synapse specific if VGCCs are opened not by large NMDA-mediated EPSPs, but instead, by amplification of BPAPs when they collide with smaller AMPA or NMDA-mediated EPSPs at active synapses. Computational modeling work suggests that the amplification of BPAPs by the EPSP can be confined to a region near the active synapse (Stuart and Hausser 2001). Thus, if VGCCs are opened by a collision between a BPAP and an EPSP, the resulting calcium entry could be restricted to synapses in which EPSPs have been evoked recently by CS stimulation. Together, calcium entry into LA neurons through both NMDARs and VGCCs during fear conditioning then activates second messenger pathways that ultimately strengthen the synapse, possibly by enhancing current influx through AMPA receptors (Fig. 2, right).

In summary, if US-elicited postsynaptic activity occurs in close enough temporal proximity to CS-elicited EPSPs, then calcium enters through both NMDARs and VGCCs at sensory input synapses in LA neurons. Calcium entry through NMDARs is triggered when the US depolarizes the dendrites of the postsynaptic cell, unblocking NMDARs that have recently bound glutamate released during the CS. In addition, calcium entry through VGCCs may also be triggered when the depolarization of the LA neuron by the US causes it to fire action potentials, which travel back into dendritic regions where they collide with CS-evoked EPSPs to open VGCCs at active synapses. Hence, pairing of the CS and US can cause conjunctive calcium entry through NMDARs and VGCCs that results in a strengthening of input synapses in LA. Such synaptic strengthening ultimately allows the CS to gain access to behavioral circuits controlling defensive responses, as discussed previously (see Fig. 1).

\section{Temporal Integration of the CS and US}

The induction of Hebbian LTP at a synapse requires specific patterns of stimulation to occur at that synapse. We have proposed that during fear conditioning, LTP at sensory inputs to LA neurons is induced by natural activity patterns that are evoked when the CS is paired with the US. Consistent with this idea, LTP in LA seems to require postsynaptic depolarization to be contingent upon (and not just contiguous with) presynaptic stimulation (Bauer et al. 2001), in much the same way that fear conditioning requires the US to be contingent upon the CS (Rescorla 1968). As proposed above, this LTP in LA may require two cooperative mechanisms for detecting the coincidence of the CS and US, one involving NMDARs, and the other involving VGCCs. To evaluate this hypothesis, it is important to consider how LA neurons respond to the CS and US, and examine whether such responses could be effective at activating NMDARs and VGCCs to induce LTP.

LA neurons are known to fire action potentials in response to both an auditory CS and an electric shock US (Romanski et al. 1993; Blair and LeDoux 2000), indicating that sensory information about the CS and US converges onto LA neurons, as predicted by our hypothesis. But do these convergent inputs cause activity patterns that can induce LTP when the CS and US are presented together?

Most of the information available about the effects of a tone CS on LA neurons comes from studies of extracellular recordings in awake or anesthetized rats (Bordi and LeDoux 1992; Quirk et al. 1995, 1997; Collins and Pare 2000; Maren 2000). These studies show that LA cells typically respond with a burst of spikes at the onset of the tone, and then fire intermittently until the tone is over. A tone CS used in fear conditioning typically lasts for many seconds (or even minutes in some studies), and coterminates with a shock US lasting hundreds or thousands of milliseconds. Therefore, the US does not occur until many seconds after the onset of the CS, during a time when the CS probably elicits only intermittent spiking from LA neurons. This raises two interrelated issues concerning the temporal coincidence of the $\mathrm{CS}$ and US during fear conditioning. First, does the tone CS continue to elicit EPSPs at auditory synapses onto LA neurons throughout the long duration of the CS up until the time when the US occurs? Second, even if EPSPs are being elicited by the CS when the US occurs, how precisely must these brief EPSPs be timed to coincide with US-evoked activation of the LA neuron in to open NMDARs and VGCCs to induce LTP?

Even though LA neurons do not reliably fire CS-evoked spikes during or just before the US, auditory neurons that project to LA may continue to provide subthreshold synaptic stimulation that evokes EPSPs at sensory inputs to LA neurons until the US occurs. That is, glutamate could be released from auditory neurons onto LA neurons continually throughout the duration of the CS, but the frequency of glutamate release events would not remain high enough to strongly depolarize the LA neuron to elicit action potentials throughout the CS. However, given that a single glutamate release event can activate NR2B-containing NMDARs for up to $300 \mathrm{~ms}$ (Monyer et al. 1994; Flint et al. 1997), even a low frequency of glutamate release might be sufficient to keep glutamate persistently bound to NMDARs (especially those containing the NR2B subunit) throughout the CS, keeping them eligible to pass calcium if the LA neuron is strongly depolarized by the US. Thus, calcium entry through NMDARs could serve to detect the coincidence of the CS and US, even if the CS-evoked glutamate release onto LA neurons occurs at a low rate during the period when the US occurs.

We have proposed that, in addition to NMDARs, LTP

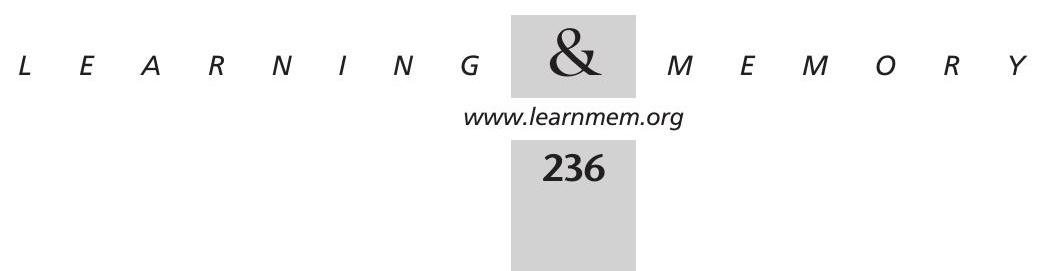


induced during fear learning also requires calcium entry through VGCCs. VGCCs may play a role in coincidence detection by allowing calcium entry when a presynaptically elicited EPSP collides with a BPAP in the postsynaptic cell (Magee and Johnston 1997). However, because EPSPs and BPAPS are both quite short in duration, a US-evoked spike in an LA neuron might have to be very precisely timed to collide with the EPSP and cause calcium entry through VGCCs. In cortical and hippocampal pyramidal cells, a single postsynaptic spike must occur within $\sim 20 \mathrm{~ms}$ following the onset of an EPSP to induce LTP (Markram et al. 1997; Bi and Poo 1998; Nishiyama et al. 2000). Furthermore, if the postsynaptic spike precedes the EPSP by $20 \mathrm{~ms}$ or less, then the synapse becomes depressed, rather than strengthened. If a similar spike time window for LTP induction exists at synaptic inputs to LA neurons, a severe timing constraint would be imposed on the natural activity patterns that can open VGCCs to induce LTP in LA during behavioral learning.

The critical spike timing window for LTP induction has not been measured precisely in LA neurons, so it is not known whether postsynaptic spikes must occur immediately after synaptic EPSPs to induce LTP in LA. Furthermore, even in the hippocampus and cortex, it is not well understood how the duration of the spike timing window is influenced by temporal summation of multiple EPSPs, or by the occurrence of multiple postsynaptic action potentials. In contrast to the 20-ms time window for LTP induction that has been observed when single EPSPs are paired with single postsynaptic spikes (Markram et al. 1997; Bi and Poo 1998; Nishiyama et al. 2000), the critical time window for LTP induction can be as long as $100 \mathrm{~ms}$ when EPSPs are paired with sustained postsynaptic depolarization that causes multiple action potentials (Gustafsson et al. 1987). This suggests that bursts of postsynaptic action potentials might be effective at inducing LTP beyond the 20-ms time window that exists for single postsynaptic spikes. Consistent with this idea, bursts of postsynaptic action potentials are more effective than single spikes at generating pairing-induced LTP in adult hippocampus (Thomas et al. 1998; Pike et al. 1999; Paulsen and Sejnowski 2000). The fact that the US can elicit a burst of action potentials from LA cells (Blair and LeDoux 2000) offers a possible means of broadening the window of plasticity and thereby reducing the necessity that a presynaptically elicited EPSP occur within $20 \mathrm{~ms}$ of a postsynaptic spike. However, it must also be considered that bursts of postsynaptic action potentials could be more effective at decreasing synaptic strength, rather than increasing it, if the burst is appropriately timed. For example, in the hippocampus, it has been found that the time window for backward pairing-induced LTD depends upon the amount of postsynaptic depolarization (DeBanne et al. 1998). Further neurophysiological studies of synaptic plasticity in LA are needed to investigate how the timing re- quirements for LTP in LA pyramidal cells might constrain temporal integration of the CS and US during auditory fear conditioning.

In summary, it is possible that LTP could be induced in LA by natural patterns of activity that occur when the CS is paired with the US, and that NMDARs and VGCCs may both play a significant role in detecting the coincidence of the CS and US. However, the timing requirements for these two coincidence detection mechanisms - NMDARs and VGCCs - may be somewhat different. NMDARs, especially those that incorporate the NR2B subunit, seem well suited to integrate CS- and US-evoked activity over long time scales (on the order of hundreds of milliseconds), whereas VGCCs may be better suited for temporal integration at shorter time scales (perhaps on the order of tens of milliseconds). Alternatively, the possibility must be considered that even though VGCCs are necessary for fear conditioning and some forms of LTP in LA (Weisskopf et al. 1999; Bauer et al. 2000), VGCCs may not function as Hebbian coincidence detectors that sense the collision between EPSPs and BPAPs. Instead, VGCCs may be opened by large NMDAmediated EPSPs (Mermelstein et al. 2000), which would occur when NMDARs detect coincident activation of CS and US inputs onto LA neurons. That is, NMDARs may detect coincident activation of CS and US inputs, whereas VGCCs merely detect strong activation of NMDARs. Future research is necessary to determine exactly what role NMDARs and VGCCs might play in Hebbian coincidence detection. Whatever their respective roles in coincidence detection may be, there is evidence that once they are activated, calcium entry through NMDARs and VGCCs may play different roles in the induction of short-term versus long-term memory of fear conditioning, the topic to which we now turn.

\section{Short and Long Term Memory}

It is well established across species and learning paradigms that long-term memory is dependent on macromolecular synthesis, whereas short-term memory is not (see Bailey et al. 1996; Schafe et al. 2001). In accordance with this tenet, blockade of protein synthesis in LA does not disrupt shortterm fear memory, but prevents the consolidation of the short-term changes into long-lasting memories (Schafe and LeDoux 2000). Long and short-term memory of fear conditioning can also be dissociated by blockade of several second-messenger pathways in LA or more globally, including the mitogen-activated protein kinase (MAPK) and protein kinase A (PKA) pathways (Bourtchouladze et al. 1998; Schafe et al. 1999, 2000; Schafe and LeDoux 2000). These findings suggest that short-term fear memories are stored by immediate synaptic changes that occur in LA when the CS is paired with the US, and these changes do not involve gene transcription or synthesis of RNA or proteins. However, for these changes to persist as long-term memories, macromolecular synthesis is necessary to consolidate the

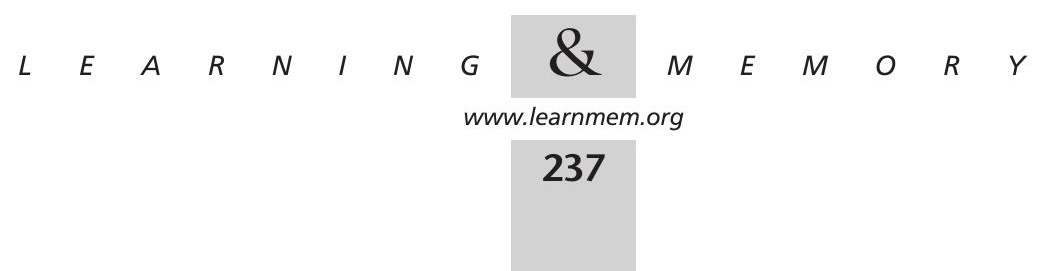


immediate short-term synaptic enhancements into permanent synaptic modifications (Schafe et al. 1999, 2000; Nader et al. 2000; Schafe and LeDoux 2000).

Interestingly, the same signaling pathways that are required for consolidating long-term fear memories in LA are also required for inducing long-lasting enhancement of synaptic transmission at LA synapses. Huang et al. (2000) investigated synaptic correlates of short and long-term fear memory by inducing two different forms of LTP in LA. The first form, called early LTP (E-LTP), produces synaptic enhancement which lasts only 60-90 min, and is induced by stimulating the input pathway with a single high-frequency tetanus. The second form, called late LTP (L-LTP), produces enhancement lasting many hours, and is induced by applying tetanic stimulation five times to the input pathway. They showed that selective impairment of L-LTP (and sparing of E-LTP) can be obtained by applying inhibitors of MAPK, PKA, and protein synthesis, the same treatments that selectively impair long-term memory (but not short term memory) of fear conditioning when they are infused into LA.

The drugs used to block L-LTP and long-term memory of fear conditioning are thought to interfere directly with macromolecular synthesis and second messenger signals that are required for the conversion of short-term synaptic potentiation into consolidated long-term changes (Huang et al. 2000; Schafe et al. 1999, 2000; Schafe and LeDoux 2000; Sweatt 2000). However, recent findings suggest additional mechanisms by which some of these drugs might cause selective impairment of L-LTP and long-term memory. For example, inhibitors of PKA and MAPK, in addition to blocking second messengers and macromolecular synthesis, may also disrupt BPAPs by allowing A-type potassium channels to open, thus shunting BPAPs and preventing them from opening VGCCs in the dendrites (Hoffman and Johnston 1998; Johnston et al. 1999; Sweatt 2000; Stuart and Hausser 2001). If calcium entry through VGCCs is needed to trigger memory consolidation mechanisms, as we have proposed here, then inhibitors of PKA and MAPK may impair LTM in two different but interrelated ways as follows: (1) by directly blocking second messengers and nuclear signaling pathways involved in memory consolidation, and (2) by preventing BPAPs from invading denrites to open VGCCs, a step which may be necessary for initially triggering the molecular signaling pathways for memory consolidation.

We therefore propose that combined calcium entry through both NMDARs and VGCCs is essential to trigger consolidation mechanisms that support long-term fear memory, but that short-term memory requires calcium entry only through NMDARs, and not through VGCCs. Several predictions follow from this hypothesis. First, blocking NMDARs in the amygdala during learning should impair both short and long-term fear memory, which is known to be the case (Walker and Davis 2000; Rodrigues et al. 2001).
Second, NMDA blockade should block both E-LTP and LLTP, which is supported by the finding that APV blocks the synaptic enhancement induced by the L-LTP protocol (Huang and Kandel 1998). However, effects of NMDA blockade on E-LTP have not been tested explicitly. Third, blockade of VGCCs should selectively block long-term but not short-term memory, a prediction for which there is preliminary support in studies of fear conditioning in LA (E.P. Bauer, G.E. Schafe, and J.E. LeDoux, in prep.) and spatial learning in hippocampus (Borroni et al. 2000). Fourth, VGCC blockade should prevent L-LTP, but not E-LTP, a prediction that has not been tested.

\section{Summary and Conclusions}

The hypothesis proposed here suggests that Hebbian plasticity in LA occurs during fear conditioning through a combination of NMDA-dependent and VGCC-dependent LTP. The main elements of this hypothesis are that when the CS is presented during fear conditioning, EPSPs are generated at sensory synaptic inputs to LA neurons from auditory cortex and/or thalamus (Bordi and LeDoux 1992; Li et al. 1996), and glutamate binds to NMDARs at these synapses (Li et al. 1995, 1996; Weisskopf and LeDoux 1999), making them eligible to pass calcium in the event of strong postsynaptic depolarization. The same LA neurons that receive input from the CS are strongly depolarized when the US occurs (Romanski et al. 1993; Blair and LeDoux 2000). This strong US-mediated depolarization unblocks eligible NMDARs (those binding glutamate) and allows elevated local calcium entry to occur at synaptic inputs recently activated by the CS (arrow 1 in Fig. 2). Calcium entry through NMDARs induces short-term LTP at the synapse, but this is not sufficient to initiate the intracellular cascades that form long-lasting memories. The latter requires that VGCCs be activated when a BPAP, which occurs when the US elicits a spike from the LA neuron, collides with an EPSP evoked at sensory synaptic inputs (arrow 3 in Fig. 2). When calcium entry through VGCCs combines with calcium entry through NMDARs at a synapse that has been activated by the CS, the two mechanisms lead to synapse-specific plasticity that is associative and enduring. Infusion of drugs that prevent calcium entry through VGCCs results in impairment of long-term fear memories (Schafe et al. 1999, 2000; Bauer et al. 2000). However, short-term fear memories remain intact unless NMDARs are also blocked, in which case both short- and longterm fear memories are abolished (Rodrigues et al. 2001). In amygdala slice experiments, different stimulation protocols can induce LTP that involves only one mechanism or the other (NMDARs or VGCCs) (Weisskopf et al. 1999; Bauer et al. 2000), but under natural conditions, we propose that both are required to achieve Hebbian associative plasticity in LA and thereby lead to the associative conditioning of fear responses to novel stimuli.

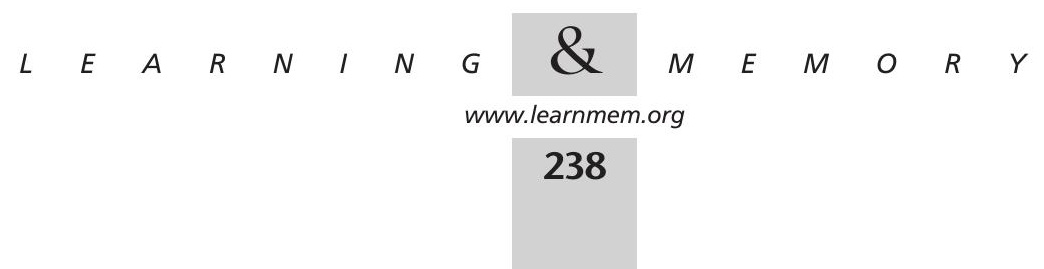




\section{ACKNOWLEDGMENTS}

This work was supported by NIMH Fellowship MH1234-02 to H.T.B., NIMH Grants MH46516, MH39774, and MH00956 to J.E.L., and by a grant to New York University from the W.M. Keck Foundation.

\section{REFERENCES}

Amorapanth, P., LeDoux, J.E., and Nader, K. 2000. Different lateral amygdala outputs mediate reactions and actions elicited by a fear-arousing stimulus. Nat. Neurosci. 3: 74-79.

Andersen, P., Sundberg, S.H., Sveen, O., and Wigstrom, H. 1977. Specific long-lasting potentiation of synaptic transmission in hippocampal slices. Nature 266: 736-737.

Aniksztejn, L. and Ben-Ari, Y. 1991. Novel form of long-term potentiation produced by a $\mathrm{K}^{+}$channel blocker in the hippocampus. Nature 349: 67-69.

Bach, M.E., Hawkins, R.D., Osman, M., Kandel, E.R., and Mayford, M. 1996. Impairment of spatial but not contextual memory in CaMKII mutant mice with a selective loss of hippocampal LTP in the range of the $\theta$ frequency. Cell 81: 905-915.

Bailey, C.H., Bartsch, D., and Kandel, E.R. 1996. Toward a molecular definition of long-term memory storage. Proc. Natl. .Acad. Sci. 93: $13445-13452$.

Bailey, D.J., Sun, W., Thompson, R.F., Kim, J.J., and Helmstetter, F.J. 1999 Acquisition of fear conditioning in rats requires the synthesis of mRNA in the amygdala. Behav. Neurosci. 113: 276-282.

Barnes, C.A. 1995. Involvement of LTP in memory: Are we "searching under the street light"? Neuron 15: 751-754.

Bauer, E.P., Schafe, G.E., and LeDoux, J.E. 2000. Different induction protocols recruit NMDA and L-type calcium channel-dependent LTP in the lateral amygdala: Correlation with fear memory. Soc. Neurosci. Abs. 26: 1253

Bauer, E.P., LeDoux, J.E., and Nader, K. 2001. Fear conditioning and LTP in the lateral amygdala are sensitive to the same stimulus contingencies. Nat. Neurosci. 4: 687-688.

Behe, P., Stern, P., Wyllie, D.J., Nassar, M., Schoepfer, R., and Colquhoun, D. 1995. Determination of NMDA NR1 subunit copy number in recombinant NMDA receptors. Proc. R. Soc. Lond. 262: 205-213.

Bi, G.Q.and Poo, M.M. 1998. Synaptic modifications in cultured hippocampal neurons: Dependence on spike timing, synaptic strength, and postsynaptic cell type. J. Neurosci. 18: 10464-10472.

Blair, H.T. and LeDoux, J.E. 2000. Single-unit recording of auditory and nociceptive responses from lateral amygdala neurons during auditory fear conditioning in freely behaving rats. Soc. Neurosci. Abs. 26: 1254 .

Blair, H.T. and LeDoux, J.E. 2001. Functional role of N-methyl-D-aspartate receptors in lateral amygdala. In Biophysical neural networks (ed. R.R. Poznanski), pp. 95-121, New York. Mary-Ann Liebert, Inc.

Blanchard, D.C. and Blanchard, R.J. 1969. Crouching as an index of fear. $J$. Comp. Physiol. Psychol. 67: 370-375.

Bliss, T.V.P. and Lomo, T. 1973. Long-lasting potentiation of synaptic transmission in the dentate area of the anaesthetized rabbit following stimulation of the perforant path. J. Physiol. 232: 331-356.

Bliss, T.V.P. and Collingridge, G.L. 1993. A synaptic model of memory: Long-term potentiation in the hippocampus. Nature 361: 31-39.

Bolles, R.C. and Fanselow, M.S. 1980. A perceptual-defensive-recuperative model of fear and pain. Behav. Brain Sci. 3: 291-323.

Bordi, F. and LeDoux, J. 1992. Sensory tuning beyond the sensory system: An initial analysis of auditory properties of neurons in the lateral amygdaloid nucleus and overlying areas of the striatum. J. Neurosci. 12: $2493-2503$

Borroni, A.M., Fichtenholtz, H., Woodside, B.L., and Teyler, T.J. 2000. Role of voltage-dependent calcium channel long-term potentiation (LTP) and NMDA LTP in spatial memory. J. Neurosci. 20: 9272-9276.

Bourtchouladz, R., Abel, T., Berman, N., Gordon, R., Lapidus, K., and Kandel, E.R. 1998. Different training procedures recruit either one or two critical periods for contextual memory consolidation, each of which requires protein synthesis and PKA. Learn. Mem. 5: 365-374.
Brown, T.H., Chapman, P.F., Kairiss, E.W., and Keenan, C.L. 1988. Long-term synaptic potentiation. Science 242: 724-728.

Cahill, L and McGaugh, J.L. 1998. Mechanisms of emotional arousal and lasting declarative memory. Trends Neurosci. 21: 294-299.

Cahill, L., Weinberger, N.M., Roozendaal, B., and McGaugh, J.L. 1999. Is the amygdala a locus of "conditioned fear"? Some questions and caveats. Neuron 23: 227-228.

Cajal, S.R. y. 1909. Histologie du systeme nerveux de l'homme et des vertebres, (ed. A. Maloine) Paris, France.

Campeau, S. and Davis, M. 1995. Involvement of subcortical and cortical afferents to the lateral nucleus of the amygdala in fear conditioning measured with fear-potentiated startle in rats trained concurrently with auditory and visual conditioned stimuli. J. Neurosci. 15: 2312-2327.

Campeau, S., Miserendino, M.J.D., and Davis, M. 1992. Intra-amygdala infusion of the N-Methyl-D-aspartate receptor antagonist AP5 blocks acquisition but not expression of fear-potentiated startle to an auditory conditioned stimulus. Behav. Neurosci. 106: 569-574.

Carew, T.J. 1996. Molecular enhancement of memory formation. Neuron 16: $5-8$

Collins, D.R. and Pare, D. 2000. Differential fear conditioning induces reciprocal changes in the sensory responses of lateral amygdala neurons to the $\mathrm{CS}(+)$ and $\mathrm{CS}(-)$ Learn. Mem. 7: 97-103.

Davis, H.P. and Squire, L.R. 1984. Protein synthesis and memory. A review. Psychol. Bull. 96: 518-559.

Davis, M. and Lee, Y. 1998. Fear and anxiety: Possible roles of the amygdala and bed nucleus of the stria terminalis. Cognit. Emotion 12: 277-305.

Davis, S., Butcher, S.P., and Morris, R.G. 1992. The NMDA receptor antagonist D-2-amino-5-phosphonopentanoate (D-AP5) impairs spatial learning and LTP in vivo at intracerebral concentrations comparable to those that block LTP in vitro. J. Neurosci. 12: 21-34.

Debanne, D., Gahwiler, B.H., and Thompson, S.M. 1998. Long-term synaptic plasticity between pairs of individual CA3 pyramidal cells in rat hippocampal slice cultures. J. Physiol. 507: 37-247.

Doron, N.N. and LeDoux, J.E. 1999. Organization of projections to the lateral amygdala from auditory and visual areas of the thalamus in the rat. J. Comp. Neurol. 412: 383-409.

Dudai, Y. 1989. The neurobiology of memory. Oxford University Press, New York.

Eccles, J.C. 1965. Conscious experience and memory. Academic address. Recent Adv. Biol. Psychiatry 8: 235-256.

Eichenbaum, H. 1997. To cortex: Thanks for the memories. Neuron 19: $481-484$

Elgersma ,Y. and Silva, A.J. 1999. Molecular mechanisms of synaptic plasticity and memory. Curr. Opin. Neurobiol. 9: 209-213.

Fanselow, M.S. and Kim, J.J. 1994. Acquisition of contextual Pavlovian fear conditioning is blocked by application of an NMDA receptor antagonist D,L-2-amino-5-phosphonovaleric acid to the basolateral amygdala. Behav. Neurosci. 108: 210-212.

Fanselow, M.S. and LeDoux, J.E. 1999. Why we think plasticity underlying Pavlovian fear conditioning occurs in the basolateral amygdala. Neuron 23: 229-232.

Farb, C.R. and LeDoux, J.E. 1997. NMDA and AMPA receptors in the lateral nucleus of the amygdala are postsynaptic to auditory thalamic afferents. Synapse 27: 106-121.

. 1999. Afferents from rat temporal cortex synapse on lateral amygdala neurons that express NMDA and AMPA receptors. Synapse 33: 218-229.

Farb, C., Aoki, C., Milner, T., Kaneko, T., and LeDoux, J. 1992. Glutamate immunoreactive terminals in the lateral amygdaloid nucleus: A possible substrate for emotional memory. Brain Res. 593: 145-158.

Farb, C.R., Aoki, C., and Ledoux, J.E. 1995. Differential localization of NMDA and AMPA receptor subunits in the lateral and basal nuclei of the amygdala: A light and electron microscopic study. J. Comp. Neurol. 362: 86-108.

Fendt, M. 2001. Injections of the NMDA receptor antagonist aminophosphonopentanoic acid into the lateral nucleus of the

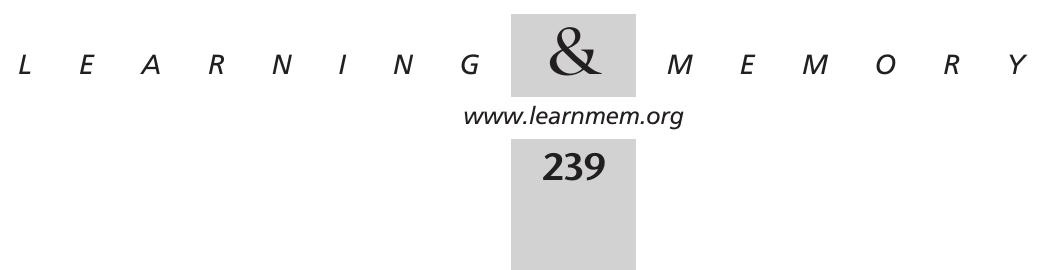


amygdala block the expression of fear-potentiated startle and freezing J. Neurosci. 21: 4111-4115.

Flint, A.C., Maisch, U.S., Weisshaupt, J.H., Kriegstein, A.R., and Monyer, H. 1997. NR2A subunit expression shortens NMDA receptor synaptic currents in developing neocortex. J. Neurosci. 17: 2469.

Frank, D.A. and Greenberg, M.E. 1994. CREB: A mediator of long-term memory from mollusks to mammals. Cell 79: 5-8.

Gean, P.W., Chang, F.C., Huang, C.C., Lin, J.H., and Way, L.J. 1993 Long-term enhancement of EPSP and NMDA receptor-mediated synaptic transmission in the amygdala. Brain Res. Bull. 31: 7-11.

Gewirtz, J.C. and Davis, M. 1997. Second-order fear conditioning prevented by blocking NMDA receptors in amygdala. Nature 388: 471-474.

Goelet, P., Castellucci, V.F., Schacher, S., and Kandel, E.R. 1986. The long and the short of long-term memory-a molecular framework. Nature 322: 419-422

Goosens, K.A. and Maren, S. 2001. Contextual and auditory fear conditioning are mediated by the lateral, basal, and central amygdaloid nuclei in rats. Learn. Mem. 8: 148-155.

Grover, L.M. and Tyler, T.J. 1990. Two components of long-term potentiation induced by different patterns of afferent activation. Nature 347: 477-479.

Gustafsson, B., Wigström, H., Abraham, W.C., and Huang, Y.Y. 1987. Long-term potentiation in the hippocampus using depolarizing current pulses as the conditioning stimulus to single volley synaptic potentials. J. Neurosci. 7: 774-780.

Hawkins, R.D., Abrams, T.W., Carew, T.J., and Kandel, E.R. 1983. A cellular mechanism of classical conditioning in Aplysia: Activity-dependent amplification of presynaptic facilitation. Science 219: 400-405.

Hebb, D.O. 1949. The organization of behavior. John Wiley and Sons, New York.

Helmstetter, F.J. and Bellgowan, P.S. 1994. Effects of muscimol applied to the basolateral amygdala on acquisition and expression of contextual fear conditioning in rats. Behav. Neurosci. 108: 1005-1009.

Hoffman, D.A. and Johnston, D. 1998. Downregulation of transient K+ channels in dendrites of hippocampal CA1 pyramidal neurons by activation of PKA and PKC. J. Neurosci. 18: 3521-3528.

Hollmann, M. and Heinemann, S. 1994. Cloned glutamate receptors. Annu. Rev, Neurosci. 17: 31-108.

Hölscher, C. 2001. Neuronal mechanisms of memory formation: Concepts of long-term potentiation and beyond. Cambridge University Press, Cambridge, UK.

Huang, Y.Y. and Kandel, E.R. 1998. Postsynaptic induction and PKA-dependent expression of LTP in the lateral amygdala. Neuron 21: $169-178$.

Huang, Y.Y., Martin, K.C., and Kandel, E.R. 2000. Both protein kinase A and mitogen-activated protein kinase are required in the amygdala for the macromolecular synthesis-dependent late phase of long-term potentiation. J. Neurosci. 20: 6317-6325.

Huber, K.M., Maukm, M.D., and Kelly, P.T. 1995. Distinct LTP induction mechanisms: Contribution of NMDA receptors and voltage-dependent calcium channels. J. Neurophysiol. 73: 270-279.

Isaac, J.T., Nicoll, R.A., and Malenka, R.C. 1995. Evidence for silent synapses: Implications for the expression of LTP. Neuron 15: $427-434$

Jaffe, D.B. Johnston, D., Lasser-Ross, N., Lisman, J.E., Miyakawa, H., and Ross, W.N. 1992. The spread of Na+ spikes determines the pattern of dendritic $\mathrm{Ca} 2+$ entry into hippocampal neurons. Nature 357: 244-246.

Johnston, D., Hoffman, D.A., Colbert, C.M., and Magee, J.C. 1999. Regulation of back-propagating action potentials in hippocampal neurons. Curr. Opin. Neurobiol. 9: 288-292.

Kandel, E.R. 1997. Genes, synapses, and long-term memory. J. Cell. Physiol. 173: 124-125.

Kandel, E.R. and Spencer, W.A. 1968. Cellular neurophysiological approaches to the study of learning. Physiol. Rev. 48: 65-134.

Kapp, B.S., Whalen, P.J., Supple, W.F., and Pascoe, J.P. 1992. Amygdaloid contributions to conditioned arousal and sensory information processing. In The amygdala: Neurobiological aspects of emotion, memory, and mental dysfunction. (ed. J.P. Aggleton), pp. 229-254. Wiley-Liss Inc., New York.

Kauer, J.A., Malenka, R.C., and Nicoll, R.A. 1988. A persistent postsynaptic modification mediates long-term potentiation in the hippocampus. Neuron 1: 911-917.

Kelso, S.R. and Brown, T.H. 1986. Differential conditioning of associative synaptic enhancement in hippocampal brain slices. Science 232: 85-87.

Kelso, S.R., Ganong, A.H., and Brown, T.H. 1986. Hebbian synapses in hippocampus. Proc. Natl. Acad. Sci. 83: 5326-5330.

Konnerth, A., Tsien, R., and Mikoshiba, K. 1996. Coincidence detection in the nervous system. Human Frontier Science Program, Strausbourg, France.

Lee, H.J. and Kim, J.J. 1998. Amygdalar NMDA receptors are critical for new fear learning in previously fear-conditioned rats. J. Neurosci. 18: 8444-8454.

Lee, H.J., Berger, S.Y., Stiedl, O., Spiess, J., and Kim, J.J. 2001a. Post-training injection of catecholaminergic drugs do not modulate fear conditioning in rats and mice. Neurosci. Lett. 303: 123-126.

Lee, H.J., Choi, J.S., Brown, T.H., and Kim, J.J. 2001b. Amygdalar $\mathrm{N}$-methyl-D-aspartate receptors are critical for the expression of multiple conditioned fear responses. J. Neurosci. 21: 4116-4124.

LeDoux, J.E. 2000. Emotion circuits in the brain. Annu. Rev. Neurosci. 23: $155-184$.

LeDoux, J.E. and Farb, C.R. 1991. Neurons of the acoustic thalamus that project to the amygdala contain glutamate. Neurosci. Lett. 134: $145-149$

LeDoux, J.E., Cicchetti, P., Xagoraris, A., and Romanski, L.M. 1990. The lateral amygdaloid nucleus: sensory interface of the amygdala in fear conditioning. J. Neurosci. 10: 1062-1069.

Levy, W.B. and Steward, O. 1979. Synapses as associative memory elements in the hippocampal formation. Brain Res. 175: 233-245.

Li, X.F., Phillips, R., and LeDoux, J.E. 1995. NMDA and non-NMDA receptors contribute to synaptic transmission between the medial geniculate body and the lateral nucleus of the amygdala. Exp. Brain Res. 105: 87-100.

Li, X.F., Stutzmann, G.E., and LeDoux, J.L. 1996. Convergent but temporally separated inputs to lateral amygdala neurons from the auditory thalamus and auditory cortex use different postsynaptic receptors: In vivo intracellular and extracellular recordings in fear conditioning pathways. Learn. Mem. 3: 229-242.

Liao, D., Hessler, N.A., and Malinow, R. 1995. Activation of postsynaptically silent synapses during pairing-induced LTP in CA1 region of hippocampal slice. Nature 375: 400-404.

Lisman, J. 1994. The CaM kinase II hypothesis for the storage of synaptic memory. Trends Neurosci. 17: 406-412.

Lynch, G.S., Dunwiddie, T., and Gribkoff, V. 1977. Heterosynaptic depression: A postsynaptic correlate of long-term potentiation. Nature 266: 737-739.

Magee, J.C. and Johnston, D. 1997. A synaptically controlled, associative signal for Hebbian plasticity in hippocampal neurons. Science 275: 209-213.

Malenka, R.C. 1991. The role of postsynaptic calcium in the induction of long-term potentiation. Mol. Neurobiol. 5: 289-295.

Malenka, R.C. and Nicoll, R.A. 1999. Long-term potentiation-a decade of progress? Science 285: 1870-1874.

Malinow, R. and Miller, J.P. 1986. Postsynaptic hyperpolarization during conditioning reversibly blocks induction of long-term potentiation. Nature 320: 529-530.

Maren, S. 1999. Long-term potentiation in the amygdala: A mechanism for emotional learning and memory. Trends Neurosci. 22: 561-7.

. 2000. Auditory fear conditioning increases CS-elicited spike firing in lateral amygdala neurons even after extensive overtraining. Eur. J. Neurosci. 12: 4047-4054.

Maren, S., Aharonov, G., Stote, D.L., and Fanselow, M.S. 1996. $\mathrm{N}$-methyl-D-aspartate receptors in the basolateral amygdala are required

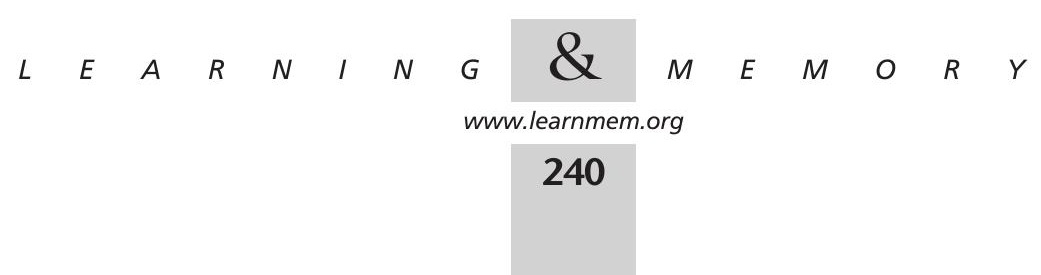


for both acquisition and expression of conditional fear in rats. Behav. Neurosci. 10: 1365-1374.

Maren, S., Yap, S.A., and Goosens, K.A. 2001. The amygdala is essential for the development of neuronal plasticity in the medial geniculate nucleus during auditory fear conditioning in rats. J. Neurosci. 21: RC135.

Markram, H., Lübke, J., Frotscher, M., and Sakmann, B. 1997. Regulation of synaptic efficacy by coincidence of postsynaptic APs and EPSPs. Science 275: 213-215.

Martin, S.J., Grimwood, P.D., and Morris, R.G.M. 2000. Synaptic plasticity and memory: An evaluation of the hypothesis. Annu. Rev. Neurosci. 23: 649-711.

Mayford, M., Bach, M.E., Huang, Y.Y., Wang, L., Hawkins, R.D., and Kandel, E.R. 1996. Control of memory formation through regulated expression of a CaMKII transgene. Science 274: 1678-1683.

McDonald, A..J. 1984. Neuronal organization of the lateral and basolateral amygdaloid nuclei of the rat. J. Comp. Neurol. 222: 589-606.

- 1998. Cortical pathways to the mammalian amygdala. Prog. Neurobiol. 55: 257-332.

McKernan, M.G. and Shinnick-Gallagher, P. 1997. Fear conditioning induces a lasting potentiation of synaptic currents in vitro. Nature 390: 607-611.

McNaughton, B.L., Douglas, R.M., and Goddard, G.V. 1978. Synaptic enhancement in fascia dentata: Cooperativity among coactive afferents. Brain Res. 157: 277-293

Mermelstein, P.G., Bito, H., Deisseroth, K., and Tsien, R.W. 2000. Critical dependence of cAMP response element-binding protein phosphorylation on L-type calcium channels supports a selective response to EPSPs in preference to action potentials. J. Neurosci. 20: $266-273$.

Miserendino, M.J.D., Sananes, C.B., Melia, K.R., and Davis, M. 1990 Blocking of acquisition but not expression of conditioned fear-potentiated startle by NMDA antagonists in the amygdala. Nature 345: 716-718

Miyakawa, H., Ross, W.N., Jaffe, D., Callaway, J.C., Lasser-Ross, N., Lisman, J.E., and Johnston, D. 1992. Synaptically activated increases in $\mathrm{Ca} 2+$ concentration in hippocampal CA1 pyramidal cells are primarily due to voltage-gated Ca2+ channels. Neuron 9: 1163-1173.

Monyer, H., Sprengel. R., Schoepfer, R., Herb, A., Higuchi, M., Lomeli, H., Burnashev, N., Sakmann, B., and Seeburg, P.H. 1992. Heteromeric NMDA receptors: Molecular and functional distinction of subtypes Science 256: 1217-1221.

Monyer, H., Burnashev, N., Laurie, D.J., Sakmann, B., and Seeburg, P.H. 1994. Developmental and regional expression in the rat brain and functional properties of four NMDA receptors. Neuron 12: 529-540.

Muller, D., Joly, M., and Lynch, G. 1988. Contributions of quisqualate and NMDA receptors to the induction and expression of LTP. Science 242: 1694-1697.

Muller, J., Corodimas, K.P., Fridel, Z., and LeDoux, J.E. 1997. Functional inactivation of the lateral and basal nuclei of the amygdala by muscimol infusion prevents fear conditioning to an explicit CS and to contextual stimuli. Behav. Neurosci. 111: 683-691.

Nader, K., Schafe, G.E., and LeDoux, J. 2000. Fear memories require protein synthesis in the amygdala for reconsolidation after retrieval. Nature 406: 722-726.

Nader, K., Majidishad, P., Amorapanth, P., and LeDoux, J.E. 2001. Damage to the lateral and central, but not other, amygdaloid nuclei prevents the acquisition of auditory fear conditioning. Learn. Mem. 8: 156-163.

Nakanishi, S. 1992. Molecular diversity of glutamate receptors and implications for brain function. Science 258: 597-603.

Nishiyama, M., Hong, K., Mikoshiba, K., Poo, M.M., and Kato, K. 2000. Calcium stores regulate the polarity and input specificity of synaptic modification. Nature 408: 584-588

Pare, D., Smith, Y., and Pare, J.F. 1995. Intra-amygdaloid projections of the basolateral and basomedial nuclei in the cat: Phaseolus vulgaris-leucoagglutinin anterograde tracing at the light and electron microscopic level. Neuroscience 69: 567-583.
Paulsen, O. and Sejnowski, T.J. 2000. Natural patterns of activity and long-term synaptic plasticity. Curr. Opin. Neurobiol. 10: 172-179.

Pike, F.G., Meredith, R.M., Olding, A.W., and Paulsen, O. 1999. Rapid report: Postsynaptic bursting is essential for 'Hebbian' induction of associative long-term potentiation at excitatory synapses in rat hippocampus. J. Physiol. 518: 571-576.

Pitkänen, A., Savander, V., and LeDoux, J.E. 1997. Organization of intra-amygdaloid circuitries in the rat: An emerging framework for understanding functions of the amygdala. Trends Neurosci. 20: $517-523$.

Poremba, A. and Gabriel, M. 2001. Amygdalar efferents initiate auditory thalamic discriminative training-induced neuronal activity. J. Neurosci 21: $270-278$.

Quirk, G.J., Repa, J.C., and LeDoux, J.E. 1995. Fear conditioning enhances short-latency auditory responses of lateral amygdala neurons: Parallel recordings in the freely behaving rat. Neuron 15: 1029-1039.

Quirk, G.J., Armony, J.L., and LeDoux, J.E. 1997. Fear conditioning enhances different temporal components of toned-evoked spike trains in auditory cortex and lateral amygdala. Neuron 19: 613-624.

Rainnie, D.G., Asprodini, E.K., and Shinnick-Gallagher, P. 1993. Intracellular recordings from morphologically identified neurons of the basolateral amygdala. J. Neurophysiol. 69: 1350-1362.

Regehr, W.G. and Tank, D.W. 1990. Postsynaptic NMDA receptor-mediated calcium accumulation in hippocampal CA1 pyramidal cell dendrites. Nature 345: 807-810.

Repa, J.C., Muller, J., Apergis, J., Desrochers, T.M., Zhou, Y., and LeDoux, J.E. 2001. Two different lateral amygdala cell populations contribute to the initiation and storage of memory. Nat. Neurosci. 4: 724-731.

Rescorla, R.A. 1968. Probability of shock in the presence and absence of CS in fear conditioning. J. Comp. Physiol. Psychol. 66: 1-5.

Rodrigues, S.M., Schafe, G.E., and LeDoux, J.E. 2001. Intraamygdala blockade of the NR2B subunit of the NMDA receptor disrupts the acquisition but not the expression of fear conditioning. J. Neurosci. 21: 6889-6896.

Rogan, M., Staubli, U., and LeDoux, J. 1997. Fear conditioning induces associative long-term potentiation in the amygdala. Nature 390: 604-607.

Rogan, M.T. and LeDoux, J.E. 1995. LTP is accompanied by commensurate enhancement of auditory - evoked responses in a fear conditioning circuit. Neuron 15: 127-136.

Rogan, M.T., Weisskopf, M.G., Huang, Y-Y., Kandel, E.R., and LeDoux, J.E. 2001. Long-term potentiation in the amygdala: Implications for memory. In Neuronal mechanisms of memory formation. (ed.C. Hölscher), pp. 58-76. Cambridge University Press, Cambridge, UK.

Romanski, L.M., LeDoux, J.E., Clugnet, M.C., and Bordi, F. 1993. Somatosensory and auditory convergence in the lateral nucleus of the amygdala. Behav. Neurosci. 107: 444-450.

Rosenblum, K., Dudai, Y., and Richter-Levin, G. 1996. Long-term potentiation increases tyrosine phosphorylation of the $\mathrm{N}$-methyl-D-aspartate receptor subunit $2 \mathrm{~B}$ in rat dentate gyrus in vivo. Proc. Natl. Acad. Sci. 93: 10457-10460.

Rosenblum, K., Berman, D.E., Hazvi, S., Lamprecht, R., and Dudai, Y. 1997. NMDA receptor and the tyrosine phosphorylation of its $2 B$ subunit in taste learning in the rat insular cortex. J. Neurosci. 17: 5129-5135.

Rostas, J.A., Brent, V.A., Voss, K., Errington, M.L., Bliss, T.V., and Gurd, J.W. 1996. Enhanced tyrosine phosphorylation of the 2B subunit of the N-methyl-D-aspartate receptor in long-term potentiation. Proc. Natl. Acad .Sci. 93: 10452-10456.

Sabatini, B.L. and Svoboda, K. 2000. Analysis of calcium channels in single spines using optical fluctuation analysis. Nature 408: 589-593.

Schafe, G.E. and LeDoux, J. 2000. Memory consolidation of auditory pavlovian fear conditioning requires protein synthesis and protein kKinase A in the amygdala. J. Neurosci. 20: RC96.

Schafe, G.E., Nadel, N.V., Sullivan, G.M., Harris, A., and LeDoux, J.E. 1999. Memory consolidation for contextual and auditory fear conditioning is dependent on protein synthesis, PKA, and MAP kinase. Learn. Mem. 6: 97-110.

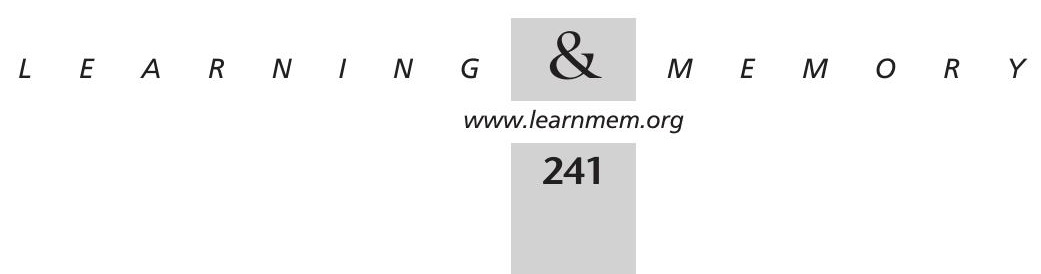


Schafe, G.E., Atkins, C.M., Swank, M.W., Bauer, E.P., Sweatt, J.D., and LeDoux, J.E. 2000. Activation of ERK/MAP kinase in the amygdala is required for memory consolidation of pavlovian fear conditioning. $J$. Neurosci. 20: 8177-8187.

Schafe, G.E., Nader, K., Blair, H.T., and LeDoux, J.E. 2001. Memory consolidation of Pavlovian fear conditioning: A cellular and molecular perspective. Trends Neurosci. 24: 540-546.

Schoepfer, R., Monyer, H., Sommer, B., Wisden, W., Sprengel, R., Kuner, T., Lomeli, H., Herb, A., Kohler, M., and Burnashev, N. 1994. Molecular biology of glutamate receptors. Prog. Neurobiol. 42: 353-357.

Smith, O.A., Astley, C.A., DeVito, J.L., Stein, JM., and Walsh, R.E. 1980. Functional analysis of hypothalamic control of the cardiovascular responses accompanying emotional behavior. Fed. Proc. 29: $2487-2494$.

Stevens, C.F. 1998. A million dollar question: Does LTP $=$ memory? Neuron 20: 1-2.

Stuart, G.J. and Hausser, M. 2001. Dendritic coincidence detection of EPSPs and action potentials. Nat. Neurosci. 4: 63-71.

Stuart, G., Spruston, N., Sakmann, B., and Hausser, M. 1997. Action potential initiation and backpropagation in neurons of the mammalian CNS. Trends Neurosci. 20: 125-131.

Sweatt, J.D. 1999. Toward a molecular explanation for long-term potentiation. Learn. Mem. 6: 399-416.

. 2000. The neuronal MAP kinase cascade: A biochemical signal integration system subserving synaptic plasticity and memory. $J$. Neurochem. 76: 1-10.

Tang, Y.P., Shimizu, E., Dube, G.R., Rampon, C., Kerchner, G.A., Zhuo, M., Liu, G., and Tsien, J.Z. 1999. Genetic enhancement of learning and memory in mice. Nature. 401: 63-9.

Thomas, M.J., Watabe, A.M., Moody, T.D., Makhinson M., and O'Dell, T.J. 1998. Postsynaptic complex spike bursting enables the induction of LTP by theta frequency synaptic stimulation. J. Neurosci. 18: 7118-7126.
Tsien, J.Z. 2000. Linking Hebb's coincidence-detection to memory formation. Curr. Opin. Neurobiol. 10: 266-273.

Tsien, J.Z., Huerta, P.T., and Tonegawa, S. 1996. The essential role of hippocampal CA1 NMDA receptor-dependent synaptic plasticity in spatial memory. Cell 87: 1327-1338.

Walker, D.L. and Davis, M. 2000. Involvement of NMDA receptors within the amygdala in short- versus long- term memory for fear conditioning as assessed with fear-potentiated startle. Behav. Neurosci. 114: 1019-1033.

Washburn, M.S. and Moises, H.C. 1992. Electrophysiological and morphological properties of rat basolateral amygdaloid neurons in vitro. J. Neurosci. 12: 4066-4079.

Watkins, J.C. and Olverman, H.J. 1987. Agonist and antagonists for excitatory amino acid receptors. Trends Neurosci. 10: 265-272.

Weinberger, N.M. 1995. Retuning the brain by fear conditioning. In The cognitive neurosciences. (ed. M.S. Gazzaniga), pp. 1071-1089. MIT Press, Cambridge, MA.

Weisskopf, M.G. and LeDoux, J.E. 1999. Distinct populations of NMDA receptors at subcortical and cortical inputs to principal cells of the lateral amygdala. J. Neurophysiol. 81: 930-934.

Weisskopf, M.G., Bauer, E.P., and LeDoux, J.E. 1999. L-Type voltage-gated calcium channels mediate NMDA-independent associative long-term potentiation at thalamic input synapses to the amygdala. J. Neurosci. 19: 10512-10519.

Wigström, H. and Gustafsson, B. 1986. Postsynaptic control of hippocampal long-term potentiation. J. Physiol. 81: 228-236.

Wilensky, A.E., Schafe, G.E., and LeDoux, J.E. 1999. Functional inactivation of the amygdala before but not after auditory fear conditioning prevents memory formation. J. Neurosci. 19: RC48.

. 2000. The amygdala modulates memory consolidation of fear-motivated inhibitory avoidance learning but not classical fear conditioning. J. Neurosci. 20: 7059-7066.

Yuste, R. and Tank, D.W. 1996. Dendritic integration in mammalian neurons, a century after Cajal. Neuron 16: 701-716. 


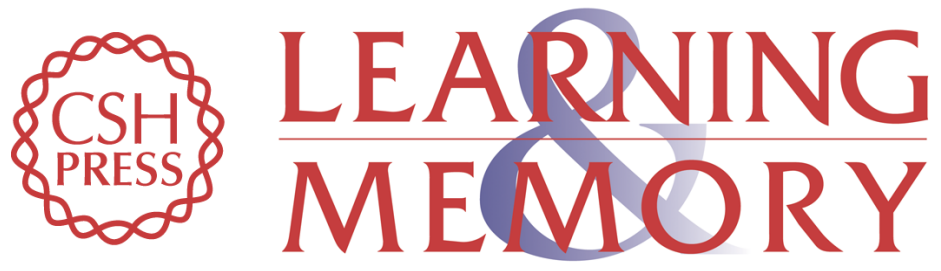

\section{Synaptic Plasticity in the Lateral Amygdala: A Cellular Hypothesis of Fear Conditioning}

Hugh T. Blair, Glenn E. Schafe, Elizabeth P. Bauer, et al.

Learn. Mem. 2001, 8:

Access the most recent version at doi:10.1101/lm.30901

References This article cites 139 articles, 43 of which can be accessed free at: http://learnmem.cshlp.org/content/8/5/229.full.html\#ref-list-1

License

Email Alerting Receive free email alerts when new articles cite this article - sign up in the box at the Service top right corner of the article or click here. 